\title{
Adaptation and validation of a Spanish version of the treatment burden questionnaire in patients with multiple sclerosis
}

María Célica Ysrraelit ${ }^{1 *}$, Marcela Paula Fiol ${ }^{1}$, Fernando Vazquez Peña ${ }^{2}$, Sandra Vanotti ${ }^{3}$, Sergio Adrián Terrasa ${ }^{2}$, Viet-Thi $\operatorname{Tran}^{4}$, Victor M. Montori ${ }^{5}$ and Jorge Correale ${ }^{1}$

\begin{abstract}
Background: The Treatment Burden Questionnaire $(\mathrm{TBQ})$ is a self-reported measure of the effect of treatment workload on patient wellbeing. We sought to validate the TBQ in Spanish and use it to estimate the burden of treatment in Argentinian patients with multiple sclerosis (MS).

Methods: The TBQ was forward-backward translated into Spanish. Two focus groups and 25 semi-structured interviews focused on wording and possible item exclusion. Validation was performed in 2 steps. First, 162 patients across a range of MS severity completed the questionnaire. Confirmatory factor analysis assessed the dimensional structure of the TBQ. Construct validity was assessed by studying correlations with fatigue and quality of life (QoL). Then, in a second cohort of 171 patients, we evaluated the association between TBQ scores and patients' sex, age, education level, employment status, type of MS, disease duration, comorbidities, EDSS, pharmacological treatment and medication adherence.
\end{abstract}

Results: The questionnaire presented a 3-factor structure in which burden was related to pharmacological treatment; comprehensive health assistance; and psycho-social-economic context. Composite reliability was $>0.8$ for all factors. TBQ showed positive correlation with fatigue $\left(r_{s}=0.467, p=0.006\right)$, negative correlation with QoL $\left(r_{s}-0.446, p=0.009\right)$. For the second cohort, total TBQ score was 43 (SD 29). Lowest scores were observed on self-monitoring $(0.53$, SD 1.3) and highest for administrative load (4.2, SD 3.4). Inverse association was found between the TBQ score and medication adherence ( $r 0.243 p=0.001$ ). TBQ scores also correlated with daily patient pill/injection requirements ( $r 0.175$ $p=0.020$ ). Individuals receiving injectable treatment scored higher than patients on oral drugs (total TBQ 51 (SD 32) vs 39 (SD 27) $p=0.002$ ).

Conclusions: The TBQ in Spanish is a reliable instrument and showed adequate correlation with QoL and adherence scales in MS patients. TBQ may benefit health resources allocation and provide tailor therapeutic interventions to construct a minimally disruptive care.

Keywords: Treatment burden, QoL, Patient-reported-outcome, Questionnaires, Multiple sclerosis, Minimally disruptive medicine

\footnotetext{
* Correspondence: mcysrraelit@fleni.org.ar

${ }^{1}$ Department of Neurology, FLENI, Buenos Aires, Argentina

Full list of author information is available at the end of the article
}

(c) The Author(s). 2019 Open Access This article is distributed under the terms of the Creative Commons Attribution 4.0 International License (http://creativecommons.org/licenses/by/4.0/), which permits unrestricted use, distribution, and reproduction in any medium, provided you give appropriate credit to the original author(s) and the source, provide a link to the Creative Commons license, and indicate if changes were made. The Creative Commons Public Domain Dedication waiver (http://creativecommons.org/publicdomain/zero/1.0/) applies to the data made available in this article, unless otherwise stated. 


\section{Background}

The burden of treatment refers to efforts patients need to make to access and use healthcare and to adhere to self-care activities (e.g., medication adherence, selfmonitoring, clinic visits, lifestyle changes) and to the negative effect these efforts have on patient wellbeing. This 'work' of being a patient $[1,2]$ requires significant investments in time, money, and physical, emotional and cognitive energy, ultimately decreasing quality of life (QoL) [3, 4].

Multiple sclerosis (MS) is a complex chronic condition often affecting individuals at the most productive stage of life. In many countries, it is the leading cause of nontraumatic disability in young adults. MS patients experience many different physical symptoms such as restricted mobility, visual deficits, balance disorders, sexual and urinary dysfunction, as well as chronic pain, among others. In addition, cognitive impairment and fatigue are present in a significant number of subjects. All of these health issues make disease burden very high in MS [5-7]. Most patients require multiple clinic visits and treatments pharmacological, physical therapy, cognitive neurorehabilitation - to manage the disease, avoid disability and maintain their quality of life. All these needs further increase the burden of comprehensive treatment. Some MS treatments involve self-administered injections or infusions, which can be extremely challenging for some patients to carry out. In one study, almost $15 \%$ of MS patients were unable to self-administer the full dose of a subcutaneously injection [8].

Patient self-assessment of their condition or of the effects of treatment varies significantly between cultures. Differences relating to concepts of health and illness, as well as of socially desirable effects are key issues when using patient-reported outcome measures in the evaluation of medicinal products, a concern shared by both EMA and FDA $[9,10]$. Several questionnaires most often developed in English, have been translated for use in other countries, and regulatory authorities are rightfully concerned about cross-cultural validity when attempting to measure the same concepts. The Treatment Burden Questionnaire (TBQ) is an instrument designed to assess the burden of treatment for different medical conditions and contexts. The instrument was first developed in a sample of patients with one or more chronic conditions in France [4], and then translated to English and adapted for use within other health systems [1]. It includes 15 items rated on a Likert scale ranging from 0 (not a problem), to 10 (significant problem). Item scores are added together to generate a total global score, ranging from 0 to 150 .

Our objective was, first, to validate the TBQ scale in Spanish in a population of MS patients; and, second, to identify specific clinical and demographic factors that were associated with patients' burden of treatment. This is important for better health resource allocation and to individualize and tailor therapeutic interventions.

\section{Methods \\ Population}

This study was carried out in patients diagnosed with MS attending the Neurology clinic at FLENI in Buenos Aires, Argentina. Inclusion criteria were: diagnosis of MS according to 2010 revisions to the McDonald criteria [11], age 18-99 years, native Spanish speakers, and ability to provide informed consent. Exclusion criteria included physical or psychological inability to complete tests and presence of relapse and/or administration of corticosteroids 4 weeks prior to assessment.

The protocol was approved by the local Ethical Committee and all participants gave written informed consent.

\section{Validation of the instrument in a first cohort of patients}

A multistep approach was used [12] to validate: 1) content 2) language and 3) psychometric properties [12].

\section{Content validation}

We studied the content validity of the TBQ for MS patients (i.e. whether the TBQ was relevant for MS patients) by answering the questions: 1) Does the TBQ adequately reflect the difficulties presented to patients with MS treatment? and 2) Is there any relevant aspect applicable to the local environment that is not taken into account by the instrument? To answer these questions, a review of studies about burden of treatment in Latin America was performed. The following databases were queried to identify relevant articles: 1 ) Medline (Pubmed), 2) EMBASE 3) Latin American and Caribbean Center on Health Sciences Information (BIREME) 4) Scientific Electronic Library on Line (SciELO) Then, two focus groups were organized: patients who consulted on an outpatient basis at the neuroimmunology department in the last month were selected to represent different clinical forms of MS (relapsing-remitting, secondary-progressive and/or primary-progressive), as well as different degrees of disability, forms of treatment and disease duration. During interviews conducted with trigger questions, domains proposed in the TBQ instrument were explored and degree of agreement with perceptions of local patients evaluated. Additional domains not included in the original version were also assessed.

\section{Language validation}

The TBQ was translated into Spanish applying a forward and backward translation procedure. The questionnaire was first translated into Argentine Spanish. Then two translations into English were carried out by native English speakers living in Argentina, both of which 
were consolidated into an initial Spanish version. The first consolidated version was then translated back into English by a different native English speaker, and this final version sent to the original author of the questionnaire and to the team that translated the original French language questionnaire into English. After approval by the original authors, a reading test was performed in $25 \mathrm{semi-}$ structured interviews where wording, level of understanding and possible exclusion of items were assessed.

\section{Psychometric validation}

In a cohort of 162 heterogeneous MS patients, the dimensional structure of the TBQ was studied with confirmatory factor analysis (CFA), using the Unweighted Least Squares estimator and the Lisrel program. Uni, bi, or tri- dimensional structures were analyzed from a conceptual point of view. In the case of two-dimensional structures, one factor was considered to be treatment burden related to medication, and the other, the remaining items combined. In the case of three-dimensional structures, items were grouped according to burden of treatment related to (1) medication, (2) healthcare, and (3) psycho-socioeconomic context. In addition, a subgroup of 33 patients also completed the following tests: Expanded Disability Status Scale (EDSS) [13], Multiple Sclerosis Functional Composite [14], Symbol Digit Modalities Test [15], Brief International Cognitive Assessment for Multiple Sclerosis [16], Multiple Sclerosis International Quality of Life Questionnaire (MSQoL) [17], Fatigue Severity Scale (FSS) [18], MOS social support scale [19], Beck Depression Inventory [20] and Hospital Anxiety and Depression Scale [21]. We studied the correlation between the TBQ and those scales using Spearman's $\left(r_{s}\right)$ and Pearson's correlation coefficients. We expected a negative correlation between burden of treatment (measured by TBQ) and QoL (measured by MSQoL); and a positive correlation between TBQ scores and fatigue (measured by FSS).

\section{Assessment of the relationships between burden of treatment and MS patients' characteristics}

In a second cohort of 171 MS patients [111 (65\%) females, mean age 42 (SD 10)] who did not participate in the first phase of the study, we investigated the association between burden of treatment, measured using the TBQ and clinical and demographic factors (sex, age, type of MS, disease duration, education level, employment status, presence of comorbidities, EDSS, pharmacological treatment and medication adherence. Adherence was assessed by the Morisky Green Levine Medication Adherence Scale (MGL) [22]. Associations were studied using Pearson's coefficient [23]. Reliability was assessed calculating composite reliability.

\section{Results}

Validation of the instrument in a first cohort of patients Content of the TBQ was tested during two focus groups and 25 semi-structured interviews in 38 MS patients (25 females), aged 43 (SD 7.9) with a mean EDSS of 2.1 (range 0-8). Patients expressed difficulties with exams, not in relation to frequency, time spent on them or associated inconveniences, but to the uncertainty generated over test results to know whether prescribed treatments were working:

"I don't care if I'm in the MRI machine for two hours, but the days following the study, while waiting to see my doctor again, are terrible for me", said a 35 yearold female patient who has been living with MS for 10 years.

Patients with MS usually require an MRI once or twice a year to assess disease activity and identify suboptimal response to treatment. This is true not only in MS but also in other chronic diseases, where evidence shows a central and disruptive role for both uncertainty over potential threats in subclinical conditions, and for clinical anxiety, that may impact patient health [24]. We therefore added a new question to the Spanish version of the TBQ to explore this item, as follows: 'How would you rate the anxiety generated by uncertainty over results of medical evaluations or tests ordered to check if your treatment is working?". As a result, the maximum TBQ score was now 160 (instead of 150). Final English version of the questionnaire is available in Additional file 1.

In contrast, items related to self-monitoring, dietary changes and recommendations to practice physical activity generated poor factorial load. Given that all three items mentioned provided important information for patients with comorbidities, these were kept in the questionnaire, but were excluded from the factor analysis. Correlation between both versions was $>0.9$ and considered equivalent [25].

Confirmatory factor analysis showed better adjustment as the number of factors included increased from 1 to 3 (Table 1 and Fig. 1).

Composite reliability $>0.8$ for all three factors. Validity of the external criterion was optimal according to reference values (25). Construct validity showed significant correlation between the TBQ and presence of fatigue measured by FSS [18] $\left(r_{\mathrm{s}}=0.467, p=0.006\right)$, as well as with QoL, measured by MSQoL [17] $\left(\mathrm{r}_{\mathrm{s}}-0.446, p=\right.$ 0.009). No correlation with EDSS or other scales was observed.

\section{Assessment of the relationships between burden of treatment and MS patients' characteristics}

After the initial validation of the questionnaire, an additional cohort of $171 \mathrm{MS}$ patients (Table 2) were surveyed 
Table 1 Factorial Validity of Treatment Burden Questionnaire

\begin{tabular}{llllll}
\hline & CFI $(>0.9)$ & NNFI $(>0.9)$ & RMSEA $(<0.08)$ & RMRs $(<0.08)$ & AGFI $(>0.9)$ \\
\hline Unifactorial & 0.89 & 0.87 & 0.13 & 0.12 & 0.90 \\
Two Factors & 0.96 & 0.95 & 0.083 & 0.077 & 0.96 \\
Three Factors & 0.98 & 0.97 & 0.063 & 0.068 & 0.96
\end{tabular}

Confirmatory Factor Analysis determining the dimensional structure of the questionnaire by use of one, two or three factors. CFI Comparative Fit Index, NNFI (Non) NormedFit Index, RMSEA Root Mean Square Error of Approximation RMRs Standardized Root Mean Square Residual, AGFI (Adjusted) Goodness of Fit

with the TBQ (Table 3). Mean total TBQ was 43 (SD 29). The lowest mean (SD) score was for the item related to self-monitoring $(0.5, \mathrm{SD} 1.3)$ and the highest for administrative load (4.2, SD 3.4). Interestingly, the new question we added about anxiety over uncertain test results to evaluate response to treatment was considered the second most important factor contributing to burden of treatment (TBQ score $=3.7$, SD 3.5). This is not comparable with previous versions of the TBQ in French or English as they had 13 or 15 questions respectively $[1,4]$.

Again, we found a significant and inverse correlation between TBQ and QoL $\left(\mathrm{r}_{\mathrm{s}}-0.446, p=0.009\right)$ and a positive correlation with fatigue $\left(\mathrm{r}_{\mathrm{s}} 0.467, p=0.006\right)$. In addition, in this cohort we found an inverse association between TBQ global score and medication adherence: the greater the treatment burden, the lower the adherence to treatment ( $\mathrm{r} 0.243 p=0.001)$. TBQ scores also showed weak correlation with number of pills or injections ( $0.175 p=0.020)$. Number of comorbidities correlated with daily number of pills or injections ( $\mathrm{r} 0.240$ $p=0.02$ ) but not with TBQ. There were no differences in TBQ scores across men and women, type of MS, disease duration or employment status. Patients receiving injectable therapies had significantly higher burden of treatment than patients taking oral drugs (TBQ total injectable 51 (SD 32) vs oral 39 (SD 27) $p=0.002)$.

\section{Discussion}

TBQ is the first reliable tool assessing treatment burden across multiple conditions and treatments [4]. We adapted a Spanish version of this instrument for patients with MS, a chronic complex neurological condition. During the process, we added a new item to the Spanish $\mathrm{TBQ}$, related to dealing with uncertain test results, not

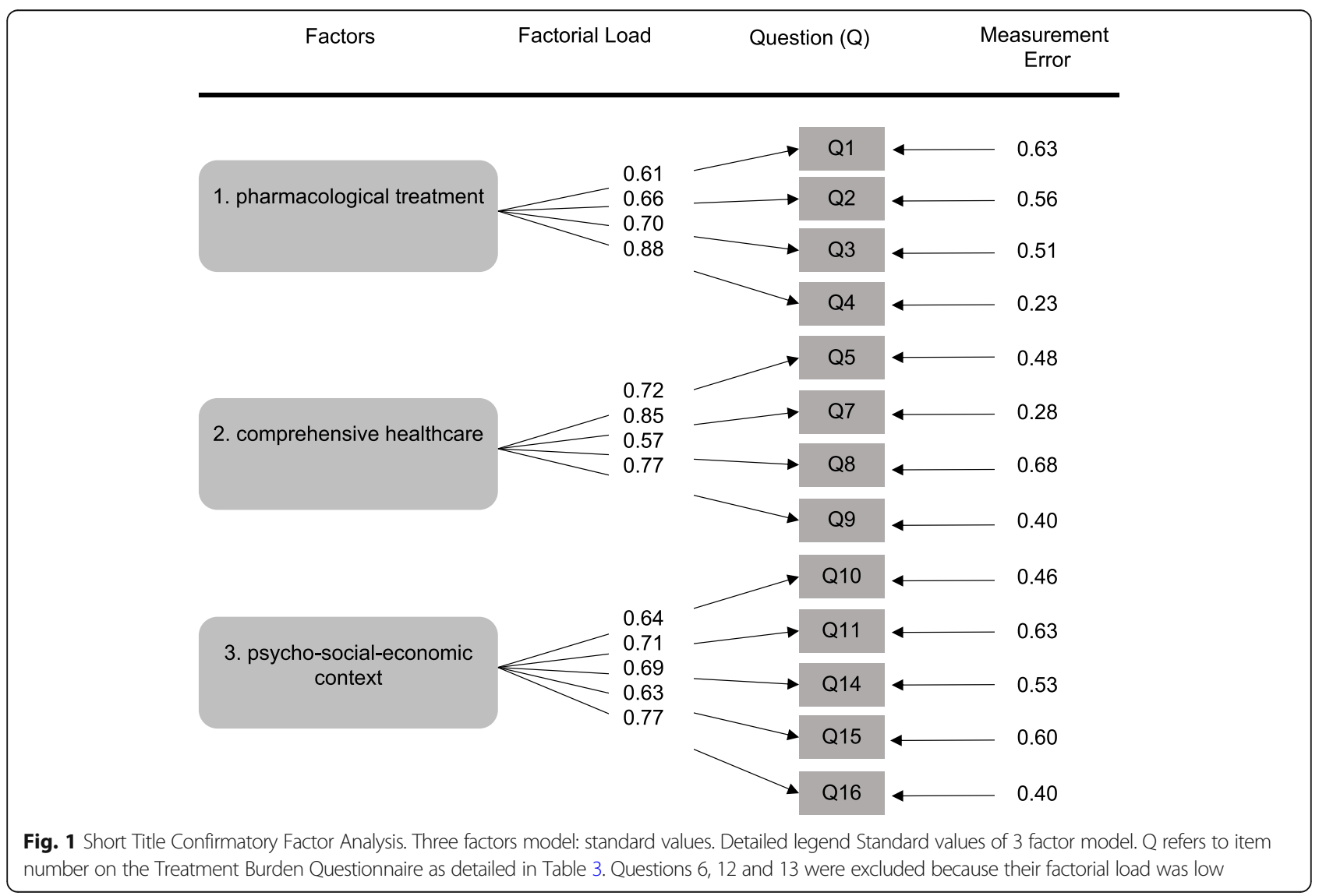


Table 2 Clinical and Demographical Data of the second cohort of MS patients

\begin{tabular}{|c|c|}
\hline Total $n$ & 171 \\
\hline Age, mean (SD) & 42 (10) years \\
\hline Women, n (\%) & $111(65)$ \\
\hline Education, mean (SD) & 17 (3.6) years \\
\hline \multicolumn{2}{|l|}{ Employment, n (\%) } \\
\hline Full time & $103(61)$ \\
\hline Part time & $30(18)$ \\
\hline Unemployed & $29(17)$ \\
\hline Retired due to disability & $8(5)$ \\
\hline \multicolumn{2}{|l|}{ Type of MS, n (\%) } \\
\hline RRMS & $133(78)$ \\
\hline PPMS & $11(7)$ \\
\hline SPMS & $11(7)$ \\
\hline $\mathrm{CIS}$ & $4(2)$ \\
\hline Unknown & $11(7)$ \\
\hline Disease Duration, mean (SD) & $9.2(7)$ years \\
\hline EDSS mean (range) & $1.86(0-9)$ \\
\hline \multicolumn{2}{|l|}{ Comorbidities, n (\%) } \\
\hline Smoking & $24(14)$ \\
\hline $\mathrm{BMI}>30$ & $24(14)$ \\
\hline Diabetes & $5(3)$ \\
\hline Hypertension & $14(9)$ \\
\hline Dyslipidaemia & $37(24)$ \\
\hline Other autoimmune disease & $24(16)$ \\
\hline \multicolumn{2}{|l|}{ Disease-Modifying Treatment, n (\%) } \\
\hline Injectable & $58(34)$ \\
\hline Oral & $73(42)$ \\
\hline Monoclonal Antibodies & $15(9)$ \\
\hline None & $21(12)$ \\
\hline $\begin{array}{l}\text { Total number of pills or injections per patient per day, } \\
\text { mean (SD) }\end{array}$ & $2.7(2.1)$ \\
\hline
\end{tabular}

included in the original English version. As expected, we found direct correlation between treatment burden and QoL (i.e., patients with higher burden had poorer QoL) and not with other measures of burden of illness.

We found a correlation between TBQ scores and fatigue. Fatigue is considered by MS patients to be one of the main causes of impaired quality of life, independent of depression or disability [26, 27] and is the most commonly reported symptom [28]. More than $25 \%$ of all patients, state fatigue as their most disabling symptom [29]. Patients overwhelmed by treatment demands may be fatigued by these demands either because of excessive workload or reduced capacity, including reduced capacity because of burden of illness.
Table $3 \mathrm{TBQ}$ final questionnaire scores per item

\begin{tabular}{|c|c|}
\hline TBQ Item & $\begin{array}{l}\text { Score, mean } \\
\text { (SD) }\end{array}$ \\
\hline $\begin{array}{l}\text { 1. The taste, shape or size of your tablets and/or } \\
\text { the annoyances by your injections }\end{array}$ & $2.6(3.2)$ \\
\hline $\begin{array}{l}\text { 2. The numbers of times you should take your } \\
\text { medication daily }\end{array}$ & $1.8(2.3)$ \\
\hline $\begin{array}{l}\text { 3. The efforts you make not to forget to take } \\
\text { your medications }\end{array}$ & $2.5(2.9)$ \\
\hline $\begin{array}{l}\text { 4. The necessary precautions when taking your } \\
\text { medication }\end{array}$ & $2.1(2.8)$ \\
\hline $\begin{array}{l}\text { 5. Lab Tests and other exams: frequency, time } \\
\text { spent and associated nuisances or inconveniences }\end{array}$ & $2.8(2.6)$ \\
\hline $\begin{array}{l}\text { 6. Self-monitoring: frequency, time spent and } \\
\text { inconveniences }\end{array}$ & $0.5(1.3)$ \\
\hline $\begin{array}{l}\text { 7. Doctor visits and other appointments: frequency, } \\
\text { time spent for these visits and difficulties findings } \\
\text { healthcare providers }\end{array}$ & $2.7(2.8)$ \\
\hline 8. Difficulties in relationships with healthcare providers & $1.6(2.6)$ \\
\hline $\begin{array}{l}\text { 9. Arranging medical appointments and/or } \\
\text { transportation and reorganizing schedules } \\
\text { around these appointments }\end{array}$ & $3.3(3.1)$ \\
\hline 10. Administrative burden related to healthcare & $4.2(3.4)$ \\
\hline 11. Financial burden associated with healthcare & $3.2(3.2)$ \\
\hline 12. Burden related to dietary changes & $2.1(2.8)$ \\
\hline $\begin{array}{l}\text { 13. Burden related to doctors recommendations } \\
\text { to practice physical activity }\end{array}$ & $3.0(3.2)$ \\
\hline 14. Impact of healthcare on relationships with others & $3.0(3.4)$ \\
\hline $\begin{array}{l}\text { 15. Anxiety generated by uncertainty over results of } \\
\text { medical checkups and complementary studies } \\
\text { to know if treatment is working }\end{array}$ & $3.6(3.5)$ \\
\hline $\begin{array}{l}\text { 16. The need for medical healthcare on a regular } \\
\text { basis reminds me of my health problem }\end{array}$ & $2.9(3.2)$ \\
\hline
\end{tabular}

We found significant differences in $\mathrm{TB}$ in patients receiving oral versus injectable therapies. This has been previously described [30,31] and is an additional factor that must be taken into account when choosing specific disease-modifying treatments for the individual patient. We also detected significant correlation between TBQ scores and medication adherence. This correlation was previously reported $[1,4]$. Non-adherence in MS is further related to suboptimal response to treatment [32], including disease relapse [32], decreased QoL, and need for more expensive healthcare, such as increased number of emergency department visits and hospitalizations [8, 33].

Other instruments to measure TB have been recently developed: the Patient Experience with Treatment and Self- management (PETS) [34] and the MedicationRelated Burden Quality of Life (MRB-QoL) tool [35]. We chose TBQ because it is a concise, user-friendly, and comprehensive measurement, whose scores can be reliably compared across future studies with potential application for research and in clinical practice. Furthermore, the evaluation of the psycho-social-economic context is 
a critical part of patient-centered care in order to promote optimal medical outcomes and psychosocial wellbeing, in patients with chronic illnesses like MS.

In the literature, many factors are considered to impact treatment load. Sav et al. have applied the term "antecedents" to describe them, and include not only those linked to disease, for example elevated number of medications or dosage forms (oral versus injections), but also individual patient characteristics including: age, sex, employment status, family support and engagement, presence of comorbidities as well as patient/ health provider relationship [36, 37]. Treatment burden is thought to result from imbalance between patient "workload" and patient "capacity". Patients with few demands but low capacity may experience more burden whereas those with many demands but high capacity, may not. Examples of patient capacity include personal attributes and skills, physical and cognitive abilities, and social and financial support [38-40].

The future of chronic care encompasses technological innovations that may help to diminish treatment burden. For example, mobile phones represent a platform increasing access to care that can help improve communication between patients and healthcare providers, thereby reducing burden associated with travel and administrative issues, which in this study population were the most significant factors associated with treatment burden [41].

A first step towards lessening treatment burden is the development of assessment tools like the TBQ. Patient experience is a concept that has been gaining attention as an element of quality healthcare. Recently, patient-reported outcomes (PROs) and patient-reported outcome measures (PROMs) have been recognized as important to improve healthcare services, clinical practice and outcome research [42]. Similarly, TB can serve as a patient reported indicator of the effect that patient work has on social, physical and psychological functioning of patients with chronic conditions [43].

Our study has some limitations. We conducted a cross-sectional study that drew mostly privately insured patients with high educational level from one medical center. This limits the applicability of our findings to patients with lower socio-economic status cared and receiving care in other health systems in whom the financial burden of treatment may dominate the picture. Longitudinal studies may be needed to better understand how burden of treatment changes with fluctuations of MS activity, emergence of comorbidity, and changes in treatment intensity over time. Finally, depending on patient family structure or social environment, patients may share the burden of treatment with informal caregivers; the burden of treatment reported by patients in these cases may underestimate the total treatment burden carried by patients and caregivers.
The concept of moving towards a future of 'minimally disruptive medicine' has been proposed, where patient care emphasizes individual preferences, takes multimorbidity into account and tries to reduce workload for patients and caregivers [2]. Patient-centered frameworks, such as minimally disruptive medicine, aim to minimize TB by optimizing the workload necessary to achieve patient goals, while boosting capacity [43]. To do this, we need to provide coordinated care, centered on the person and not on the disease. Simple questions from treating physicians could be the first step in this direction, for example: "Can you really do what I am asking you to do?" [44].

\section{Conclusion}

We have produced a valid Spanish version of the TBQ and demonstrated its value in characterizing for the first time the burden of treatment in patients with MS in Latin America. Our results may help physicians better understand and identify patients who are overwhelmed by the complexity of their treatment, and highlights the need to change the current paradigm toward minimally disruptive medicine [2].

\section{Additional file}

Additional file 1: Final English language version of the Treatment Burden Questionnaire developed specifically for this study and complete references of all other questionnaires used in this study. (DOCX 17 kb)

\section{Acknowledgements}

We thank Dr. Carla Perrota for her initial help in the conception and design of work.

\section{Authors' contributions}

MCY has made substantial contributions to the conception, design of the work; acquisition, analysis and interpretation of data; has drafted the work. MPF has made substantial contributions to the conception, design of the work; acquisition, analysis and interpretation of data; has drafted the work and substantively revised it. FVP has made substantial contributions to the conception, design of the work; analysis and interpretation of data; has substantively revised the work. SV has made substantial contributions to the acquisition, analysis and interpretation of data; has substantively revised the work. ST has made substantial contributions to the conception, design of the work; analysis and interpretation of data; has substantively revised the work. VTT has made substantial contributions to the conception, design of the work; interpretation of data and has substantively revised the work. VM has made substantial contributions to the conception, design of the work; interpretation of data and has substantively revised the work. JC has made substantial contributions to the conception, interpretation of data, has drafted the work and substantively revised it. All authors have read and approved the final version of the manuscript.

\section{Funding}

This study was supported by Novartis IIT. The support by the company did not influence the design of the study, collection, analysis or interpretation of the data or writing of the article. The company had not had access to the data before the final version of the article.

Availability of data and materials

The datasets used and/or analyzed during the current study are available from the corresponding author on reasonable request. 


\section{Ethics approval and consent to participate}

The protocol was approved by our local Ethical Committee: Comité de Etica en Investigación, Fundación Lucha Enfermedades Neurológicas de la Infancia (FLENI). All participants gave written informed consent.

\section{Consent for publication}

Not applicable

\section{Competing interests}

In the last three years:

Dr. Ysrraelit has received reimbursement for developing educational presentations, advisory boards and travel/accommodations stipends from Merck Argentina, Biogen, Sanofi-Genzyme, Bayer Inc., Roche and Novartis Argentina.

Dr. Fiol has received reimbursement for developing educational presentations, advisory boards and travel/accommodations stipends from Merck Argentina, Biogen Argentina, Genzyme Argentina, Bayer Inc., Novartis Argentina and TEVA Argentina.

Dr. Vasquez Peña has received reimbursement for research coaching presentations and travel/accommodations stipends by Fundación MF para el Desarrollo de la Medicina Familiar y la Atención Primaria, Argentina. Dr. S Vanotti has received reimbursement for developing educational presentations from Biogen Argentina and Novartis Argentina.

Dr. Terrasa has received reimbursement for research coaching presentations and travel/accommodations stipends by Fundación MF para el Desarrollo de la Medicina Familiar y la Atención Primaria, Argentina.

Dr. Tran has nothing to disclose.

Dr. Montori has nothing to disclose.

Dr. Correale is a board member of Merck-Serono Argentina, Novartis Argentina, Genzyme LATAM, Genzyme global, Biogen-Idec LATAM, and Merck-Serono LATAM. He is part of the Steering Committee for the clinical trials of Ofatumumab (Novartis Global). Dr. Correale has received reimbursement for developing educational presentations for Merck-Serono Argentina, Merck-Serono LATAM, Biogen-Idec Argentina, Genzyme Argentina, Novartis Argentina, Novartis LATAM, Novartis Global, and TEVA Argentina as well as professional travel/accommodations stipends.

\section{Author details}

${ }^{1}$ Department of Neurology, FLENI, Buenos Aires, Argentina. ${ }^{2}$ Hospital Italiano de Buenos Aires (HIBA), Buenos Aires, Argentina. ${ }^{3}$ Multiple Sclerosis Clinic, INEBA - Neurosciences Institute of Buenos Aires, Buenos Aires, Argentina. ${ }^{4}$ Centre of Research in Epidemiology and Statistics (CRESS - UMR 1153), Paris, France. ${ }^{5}$ Knowledge and Evaluation Research Unit, Mayo Clinic, Rochester, MN 55905, USA.

Received: 21 May 2019 Accepted: 21 August 2019

Published online: 27 August 2019

\section{References}

1. Tran V-T, Harrington M, Montori VM, Barnes C, Wicks P, Ravaud P. Adaptation and validation of the Treatment Burden Questionnaire (TBQ) in English using an internet platform. BMC Med [Internet]. 2014 [cited 2018 Sep 4];12(1):109. Available from: http://www.ncbi.nlm.nih.gov/pubmed/24989988

2. May C, Montori VM, Mair FS. We need minimally disruptive medicine. BMJ [Internet] 2009 [cited 2019 Jan 21];339(aug11 2):b2803-b2803. Available from: http://www.ncbi.n/m.nih.gov/pubmed/19671932.

3. May CR, Eton DT, Boehmer K, Gallacher K, Hunt K, Macdonald S, et al. Rethinking the patient: using Burden of Treatment Theory to understand the changing dynamics of illness [Internet]. Vol. 14. 2014 [cited 2018 Sep 4]. Available from: http://www.biomedcentral.com/1472-6963/14/281

4. Tran V-T, Montori VM, Eton DT, Baruch D, Falissard B, Ravaud P. Development and description of measurement properties of an instrument to assess treatment burden among patients with multiple chronic conditions. BMC Med [Internet]. 2012 [cited 2018 Sep 4];10(1):68. Available from: http://www.ncbi.n/m.nih.gov/pubmed/22762722

5. Kobelt G, Thompson A, Berg J, Gannedahl M, Eriksson J, MSCOI Study Group the MS, et al. New insights into the burden and costs of multiple sclerosis in Europe. Mult Scler [Internet]. 2017 [cited 2019 Jan 16];23(8):1123-1136. Available from: http://www.ncbi.nlm.nih.gov/pubmed/28273775

6. Gold R, Toumi M, Meesen B, Fogarty E. The payer's perspective: what is the burden of MS and how should the patient's perspective be integrated in health technology assessment conducted for taking decisions on access to care and treatment? Mult Scler [Internet]. 2016 [cited 2019 Jan 16];22(2 Suppl):60-70. Available from: http://journals.sagepub.com/doi/10.1177/1352458516650743

7. Kobelt G, Eriksson J, Phillips G, Berg J. The burden of multiple sclerosis 2015: Methods of data collection, assessment and analysis of costs, quality of life and symptoms. Mult Scler J [Internet]. 2017 [cited 2019 Jan 16];23(2_suppl): 4-16. Available from: http://www.ncbi.nlm.nih.gov/pubmed/28643592

8. Wicks P, Massagli M, Kulkarni A, Dastani H. Use of an online community to develop patient-reported outcome instruments: the multiple sclerosis treatment adherence questionnaire (MS-TAQ). J Med Internet Res [Internet]. 2011 [cited 2019 Jan 17];13(1):e12. Available from: http://www.ncbi.nlm.nih. gov/pubmed/21266318

9. Agency EM. EMEA HRQL Guidance. 2005 [cited 2019 Feb 15];(July). Available from: http://www.emea.eu.int

10. U.S. Department of Health and Human Services FDA Center for Drug Evaluation and Research, U.S. Department of Health and Human Services FDA Center for Biologics Evaluation and Research, U.S. Department of Health and Human Services FDA Center for Devices and Radiological Health. Guidance for industry: patient-reported outcome measures: use in medical product development to support labeling claims: draft guidance. Health Qual Life Outcomes [Internet]. 2006 [cited 2019 Feb 15];4(1):79. Available from: http://www.ncbi.nlm.nih.gov/pubmed/17034633

11. Polman $\mathrm{CH}$, Reingold SC, Banwell B, Clanet M, Cohen JA, Filippi M, et al. Diagnostic criteria for multiple sclerosis: 2010 revisions to the McDonald criteria. Ann Neurol [Internet]. 2011 [cited 2019 Jan 24];69(2):292-302. Available from: http://doi.wiley.com/10.1002/ana.22366

12. Acquadro C, Conway K, Hareendran A, Aaronson N, European Regulatory Issues and Quality of Life Assessment (ERIQA) Group. Literature Review of Methods to Translate Health-Related Quality of Life Questionnaires for Use in Multinational Clinical Trials. Value Heal [Internet]. 2008 [cited 2019 Jan 10];11(3): 509-521. Available from: http://www.ncbi.nlm.nih.gov/pubmed/18179659

13. Kurtzke JF. Rating neurologic impairment in multiple sclerosis: an expanded disability status scale (EDSS). Neurology [Internet]. 1983 [cited 2019 Feb 6];33(11):1444-1452. Available from: http://www.ncbi.nlm.nih. gov/pubmed/6685237

14. Cutter GR, Baier ML, Rudick RA, Cookfair DL, Fischer JS, Petkau J, et al. Development of a multiple sclerosis functional composite as a clinical trial outcome measure. Brain [Internet]. 1999 [cited 2019 Feb 6];122 ( Pt 5):871882. Available from: http://www.ncbi.n/m.nih.gov/pubmed/10355672

15. Benedict RH, DeLuca J, Phillips G, LaRocca N, Hudson LD, Rudick R, et al. Validity of the Symbol Digit Modalities Test as a cognition performance outcome measure for multiple sclerosis. Mult Scler J [Internet]. 2017 [cited 2019 Feb 6]; 23(5):721-733. Available from: http://www.ncbi.nlm.nih.gov/pubmed/28206827

16. Langdon DW, Amato MP, Boringa J, Brochet B, Foley F, Fredrikson S, et al. Recommendations for a Brief International Cognitive Assessment for Multiple Sclerosis (BICAMS). Mult Scler [Internet]. 2012 [cited 2019 Feb 6];18(6):891-898. Available from: http://journals.sagepub.com/doi/10.1177/1352458511431076

17. Vickrey BG, Hays RD, Harooni R, Myers LW, Ellison GW. A health-related quality of life measure for multiple sclerosis. Qual Life Res [Internet]. 1995 [cited 2019 Feb 6];4(3):187-206. Available from: http://www.ncbi.nlm.nih. gov/pubmed/7613530

18. Krupp LB, LaRocca NG, Muir-Nash J, Steinberg AD. The fatigue severity scale. Application to patients with multiple sclerosis and systemic lupus erythematosus. Arch Neurol [Internet]. 1989 [cited 2019 Feb 6];46(10):1121-1123. Available from: http://www.ncbi.nlm.nih.gov/pubmed/2803071

19. Sherbourne CD, Stewart AL. The MOS social support survey. Soc Sci Med [Internet]. 1991 [cited 2019 Feb 6];32(6):705-714. Available from: http:// www.ncbi.nlm.nih.gov/pubmed/2035047

20. BECK AT, WARD CH, MENDELSON M, MOCK J, ERBAUGH J. An inventory for measuring depression. Arch Gen Psychiatry [Internet]. 1961 [cited 2019 Feb 6]; 4:561-571. Available from: http://www.ncbi.nlm.nih.gov/pubmed/13688369

21. Zigmond AS, Snaith RP. The hospital anxiety and depression scale. Acta Psychiatr Scand [Internet]. 1983 [cited 2019 Feb 6];67(6):361-370. Available from: http://www.ncbi.nlm.nih.gov/pubmed/6880820

22. Morisky DE, Green LW, Levine DM. Concurrent and predictive validity of a self-reported measure of medication adherence. Med Care [Internet]. 1986 [cited 2019 Feb 6];24(1):67-74. Available from: http://www.ncbi.nlm.nih.gov/ pubmed/3945130

23. Gorgas JG, Cardiel NL, Zamorano JC. Estadística Básica para Estudiantes de Ciencias [Internet]. 2011. 258 p. Available from: http://webs.ucm.es/info/ Astrof/users/jaz/ESTADISTICA/libro_GCZ2009.pdf 
24. Grupe DW, Nitschke JB. Uncertainty and anticipation in anxiety: an integrated neurobiological and psychological perspective. Nat Rev Neurosci [Internet]. 2013 [cited 2019 Jan 17];14(7):488-501. Available from: http://www.ncbi.nlm.nih.gov/pubmed/23783199

25. Streiner DL. A checklist for evaluating the usefulness of rating scales. Can Psychiatr [Internet]. 1993 [cited 2019 Feb 9];38(2):140-148. Available from: http://www.ncbi.nlm.nih.gov/pubmed/8467441

26. Manjaly Z-M, Harrison NA, Critchley HD, Do CT, Stefanics G, Wenderoth N, et al. Pathophysiological and cognitive mechanisms of fatigue in multiple sclerosis. J Neurol Neurosurg Psychiatry [Internet] 2019 [cited 2019 Feb 17]; jnnp-2018-320050. Available from: http://jnnp.bmj.com/lookup/doi/10.1136/ jnnp-2018-320050.

27. Mateen FJ, Manalo NC, Grundy SJ, Houghton MA, Hotan GC, Erickson H, et al. Light therapy for multiple sclerosis-associated fatigue. Medicine (Baltimore) [Internet]. 2017 [cited 2019 Feb 17];96(36):e8037. Available from: http://www.ncbi.nlm.nih.gov/pubmed/28885372

28. Krupp L. Fatigue is intrinsic to multiple sclerosis (MS) and is the most commonly reported symptom of the disease. Mult Scler [Internet]. 2006 [cited 2019 Feb 17];12(4):367-368. Available from: http://journals.sagepub. com/doi/10.1191/135248506ms1373ed

29. Ysrraelit MC, Fiol MP, Gaitán MI, Correale J. Quality of life assessment in multiple sclerosis: different perception between patients and neurologists. Front Neurol [Internet]. 2018 [cited 2019 Jan 23];8:729. Available from: http://www.ncbi.nlm.nih.gov/pubmed/29375468

30. Thach A V., Brown CM, Herrera V, Sasane R, Barner JC, Ford KC, et al. Associations Between Treatment Satisfaction, Medication Beliefs, and Adherence to Disease-Modifying Therapies in Patients with Multiple Sclerosis. Int J MS Care [Internet]. 2018 [cited 2019 Jan 22];20(6):251-259. Available from: http://www.ncbi.nlm.nih.gov/pubmed/30568562

31. Hiquera L, Carlin CS, Anderson S. Adherence to Disease-Modifying Therapies for Multiple Sclerosis. J Manag Care Spec Pharm [Internet]. 2016 [cited 2019 Jan 22];22(12):1394-1401. Available from: http://www.ncbi.nlm.nih.gov/ pubmed/27882830

32. Cohen BA, Coyle PK, Leist T, Oleen-Burkey MA, Schwartz M, Zwibel H. Therapy optimization in multiple sclerosis: a cohort study of therapy adherence and risk of relapse. Mult Scler Relat Disord [Internet]. 2015 [cited 2019 Jan 22];4(1):75-82. Available from: http://www.ncbi.nlm.nih.gov/ pubmed/25787057

33. Evans C, Marrie RA, Zhu F, Leung S, Lu X, Kingwell E, et al. Adherence to disease-modifying therapies for multiple sclerosis and subsequent hospitalizations. Pharmacoepidemiol Drug Saf [Internet]. 2017 [cited 2019 Jan 22];26(6):702-711. Available from: http://www.ncbi.nlm.nih.gov/ pubmed/28370875

34. Eton DT, Yost KJ, Lai J, Ridgeway JL, Egginton JS, Rosedahl JK, et al. Development and validation of the Patient Experience with Treatment and Self-management (PETS): a patient-reported measure of treatment burden. Qual Life Res [Internet]. 2017 [cited 2019 Jan 21];26(2):489-503. Available from: http://www.ncbi.n/m.nih.gov/pubmed/27566732

35. Mohammed MA, Moles RJ, Hilmer SN, Kouladjian O'Donnel L, Chen TF. Development and validation of an instrument for measuring the burden of medicine on functioning and well-being: the medication-related burden quality of life (MRB-QoL) tool. BMJ Open [Internet]. 2018 [cited 2019 Jan 20]; 8(1):e018880. Available from: http://www.ncbi.nlm.nih.gov/pubmed/29330175

36. Sav A, King MA, Whitty JA, Kendall E, McMillan SS, Kelly F, et al. Burden of treatment for chronic illness: a concept analysis and review of the literature. Health Expect [Internet]. 2015 [cited 2019 Jan 19];18(3):312-324. Available from: http://www.ncbi.n/m.nih.gov/pubmed/23363080

37. Sav A, Salehi A, Mair FS, McMillan SS. Measuring the burden of treatment for chronic disease: implications of a scoping review of the literature. BMC Med Res Methodol [Internet]. 2017 [cited 2019 Jan 15];17(1):140. Available from: http://www.ncbi.n/m.nih.gov/pubmed/28899342

38. Ridgeway JL, Egginton JS, Tiedje K, Linzer M, Boehm D, Poplau S, et al. Factors that lessen the burden of treatment in complex patients with chronic conditions: a qualitative study. Patient Prefer Adherence [Internet]. 2014 [cited 2018 Sep 4];8:339-351. Available from: http://www.ncbi.nlm.nih. gov/pubmed/24672228

39. Gallacher KI, May CR, Langhorne P, Mair FS. A conceptual model of treatment burden and patient capacity in stroke. BMC Fam Pract [Internet]. 2018 [cited 2019 Jan 24];19(1):9. Available from: https://bmcfampract. biomedcentral.com/articles/10.1186/s12875-017-0691-4
40. Boehmer KR, Kyriacou M, Behnken E, Branda M, Montori VM. Patient capacity for self-care in the medical record of patients with chronic conditions: a mixed-methods retrospective study. BMC Fam Pract [Internet]. 2018 [cited 2019 Feb 24];19(1):164. Available from: http://www.ncbi.n/m.nih. gov/pubmed/30285746

41. Heckman BW, Mathew AR, Carpenter MJ. Treatment burden and treatment fatigue as barriers to health chronic disease and health behaviors HHS public access. 2015 [cited 2018 Sep 4];5:31-36. Available from: https://www. ncbi.nlm.nih.gov/pmc/articles/PMC4465180/pdf/nihms673094.pdf

42. Mohammed MA, Moles RJ, Chen TF. Medication-related burden and patients' lived experience with medicine: a systematic review and metasynthesis of qualitative studies. BMJ Open [Internet]. 2016 [cited 2019 Jan 20];6(2):e010035. Available from: http://www.ncbi.nlm.nih.gov/ pubmed/26839015

43. Spencer-Bonilla G, Quiñones AR, Montori VM, International Minimally Disruptive Medicine Workgroup. Assessing the Burden of Treatment. J Gen Intern Med [Internet]. 2017 [cited 2018 Sep 4];32(10):1141-1145. Available from: http://www.ncbi.nlm.nih.gov/pubmed/28699060

44. Mair FS, May CR. Thinking about the burden of treatment. BMJ [Internet]. 2014 [cited 2019 Jan 21];349(nov10 4):g6680-g6680. Available from: http://www.ncbi.nlm.nih.gov/pubmed/25385748

\section{Publisher's Note}

Springer Nature remains neutral with regard to jurisdictional claims in published maps and institutional affiliations.
Ready to submit your research? Choose BMC and benefit from:

- fast, convenient online submission

- thorough peer review by experienced researchers in your field

- rapid publication on acceptance

- support for research data, including large and complex data types

- gold Open Access which fosters wider collaboration and increased citations

- maximum visibility for your research: over $100 \mathrm{M}$ website views per year

At BMC, research is always in progress.

Learn more biomedcentral.com/submissions 